\title{
Wind-Forced Variability of the Remote Meridional Overturning Circulation
}

\author{
Michael A. Spall AND David Nieves \\ Woods Hole Oceanographic Institution, Woods Hole, Massachusetts
}

(Manuscript received 8 August 2019, in final form 5 November 2019)

\begin{abstract}
The mechanisms by which time-dependent wind stress anomalies at midlatitudes can force variability in the meridional overturning circulation at low latitudes are explored. It is shown that winds are effective at forcing remote variability in the overturning circulation when forcing periods are near the midlatitude baroclinic Rossby wave basin-crossing time. Remote overturning is required by an imbalance in the midlatitude mass storage and release resulting from the dependence of the Rossby wave phase speed on latitude. A heuristic theory is developed that predicts the strength and frequency dependence of the remote overturning well when compared to a two-layer numerical model. The theory indicates that the variable overturning strength, relative to the anomalous Ekman transport, depends primarily on the ratio of the meridional spatial scale of the anomalous wind stress curl to its latitude. For strongly forced systems, a mean deep western boundary current can also significantly enhance the overturning variability at all latitudes. For sufficiently large thermocline displacements, the deep western boundary current alternates between interior and near-boundary pathways in response to fluctuations in the wind, leading to large anomalies in the volume of North Atlantic Deep Water stored at midlatitudes and in the downstream deep western boundary current transport.
\end{abstract}

\section{Introduction}

The Atlantic meridional overturning circulation (AMOC) transports significant quantities of heat and freshwater and, as such, represents an important component of the global climate system (Ganachaud and Wunsch 2003; Lumpkin and Speer 2007). Variability in the AMOC is correlated with variability in sea surface temperature, air-sea fluxes, and heat storage in the ocean (Williams et al. 2014; Häkkinen et al. 2015; Evans et al. 2017). The mean AMOC at $26.5^{\circ} \mathrm{N}$ is approximately $17 \mathrm{~Sv}\left(1 \mathrm{~Sv} \equiv 10^{6} \mathrm{~m}^{3} \mathrm{~s}^{-1}\right)$ and the mean meridional heat transport is approximately $1.25 \mathrm{PW}$, which represents $90 \%$ of the oceanic heat transport at this latitude (McCarthy et al. 2015). The oceanic circulation is composed of several flow components. Near the surface (within the thin Ekman layer) there is an Ekman transport driven by local wind stress that is generally equatorward at midlatitudes and poleward at $26.5^{\circ} \mathrm{N}$. Below the Ekman layer in the main thermocline, flow is geostrophic and driven by the wind stress curl, where the flow is equatorward in the subtropical gyre and poleward in the subpolar gyre. Near the western boundary there is northward (southward) flow in the western

\footnotetext{
Corresponding author: Michael Spall, mspall@whoi.edu
}

boundary current of the subtropical (subpolar) gyre, while the flow of the middepth North Atlantic Deep Water is southward at all latitudes. The AMOC can be defined in either depth or density coordinates, although at midlatitudes the mean AMOC is similar in both coordinate systems.

Observations from the RAPID-MOCHA array at $26.5^{\circ} \mathrm{N}$ reveal that the AMOC varies by $O(50 \%)$ on time scales of weeks (Cunningham et al. 2007) to seasonal (Kanzow et al. 2010) to interannual (McCarthy et al. 2012). The variability can arise through natural internal modes or it may be directly forced by the atmosphere. Grégorio et al. (2015) find that externally forced lowfrequency (subseasonal) variability is dominant over natural internal variability over most of the Atlantic Ocean, especially so away from the latitude of the Gulf Stream separation. The atmosphere can force variability in the AMOC through changes in buoyancy forcing (heat flux or freshwater flux) or through changes in the wind stress. Changes in the buoyancy flux can change the water mass transformation, or overturning in density space, over wide regions of the near surface ocean. Such changes can also alter the locations and depths of the deepest convection, generally found in the Greenland Sea, Labrador Sea (Marshall and Schott 1999), and, more intermittently, the Irminger Sea (Pickart et al. 2003; 
de Jong and de Steur 2016). However, two-layer winddriven isopycnal models are able to reproduce both the seasonal variability (Kanzow et al. 2010; Zhao and Johns 2014a; Yang 2015) and interannual variability (Zhao and Johns 2014b; Pillar et al. 2016) observed by the RAPID-MOCHA array. Each of these models used realistic domains, bottom topography, and wind stresses applied to the time period of the RAPID-MOCHA array starting in 2004. Yang (2015) found that much of the seasonal variability in AMOC within the subtropical gyre resulted from wind stress anomalies within the latitude range of the subpolar gyre, indicating that AMOC variability can be remotely forced by winds.

This previous work demonstrates that AMOC varies on all time scales and is subject to numerous forcing mechanisms, both internal and external to the ocean. Wind forcing is clearly important on seasonal to interannual time scales at midlatitudes. While some correlation is expected based on the barotropic ideas of Bryan (1982) and Jayne and Marotzke (2001), these more recent studies find that at seasonal and longer time scales the response is both baroclinic and nonlocal. The purpose of the present study is to illustrate the underlying physics of how midlatitude wind stress anomalies can force low-latitude variability in the AMOC.

\section{A two-layer numerical model}

The wind-driven variability of the meridional overturning circulation is first explored using a two-layer primitive equation model on the equatorial beta-plane. The basic application under consideration here is the influence of temporal variations in midlatitude zonal wind stress on both the local and remote overturning circulation in density coordinates. The model configuration and forcing are idealized in order to easily isolate and interpret the controlling physics.

The horizontal momentum equations can be written for two isopycnal layers as

$$
\begin{aligned}
& D_{t} \mathbf{u}_{1}+\mathbf{f} \times \mathbf{u}_{1}=\frac{\boldsymbol{\tau}}{\rho_{0} h_{1}}-g \nabla\left(h_{1}+h_{2}\right)+A \nabla^{2} \mathbf{u}_{1}, \\
& D_{t} \mathbf{u}_{2}+\mathbf{f} \times \mathbf{u}_{2}=-g \nabla\left(h_{1}+h_{2}\right)+g^{\prime} \nabla h_{1}+A \nabla^{2} \mathbf{u}_{2},
\end{aligned}
$$

where

$$
D_{t}=\frac{\partial}{\partial t}+\mathbf{u} \cdot \nabla, \quad g^{\prime}=\left(\rho_{2}-\rho_{1}\right) g / \rho_{2},
$$

$\rho_{0}$ is a reference density, and $\mathbf{u}_{1}$ and $\mathbf{u}_{2}$ are the velocities in layers 1 and 2 . The wind stress vector is purely zonal, i.e., $\boldsymbol{\tau}=\left(\tau^{x}, 0\right)$. The constant Laplacian viscosity with coefficient $A$ is used for momentum dissipation.

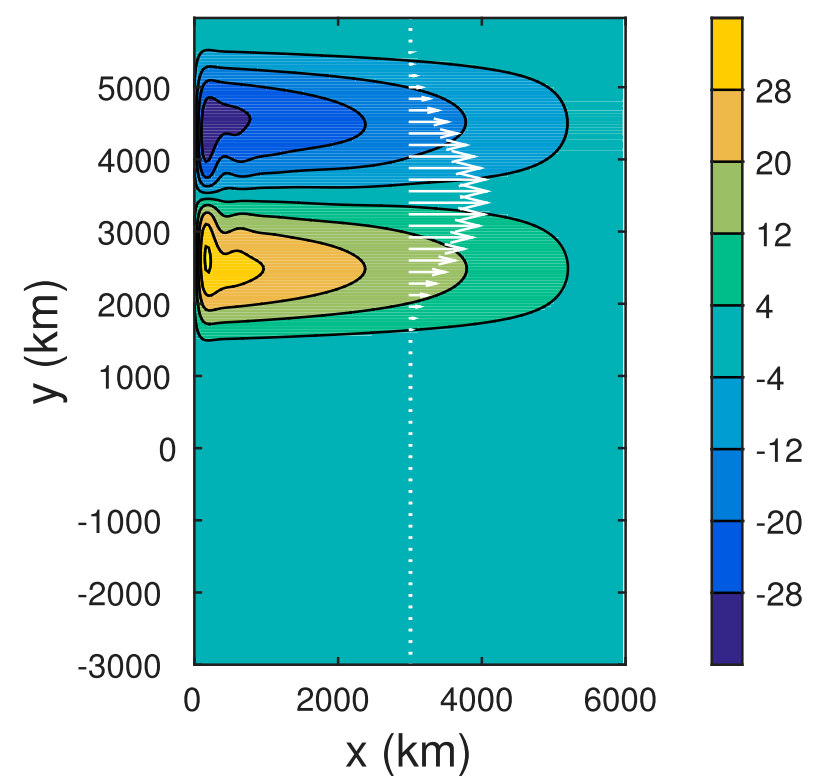

FIG. 1. The model domain, wind stress pattern, and mean upper layer transport streamfunction (Sv) for the case with no mean deep western boundary current.

The continuity equation for $k=1,2$, with no diapycnal mixing between layers, is

$$
\frac{\partial h_{k}}{\partial t}+\nabla \cdot\left(h_{k} \mathbf{u}_{k}\right)=0
$$

The Coriolis parameter varies linearly with $y$ as $\mathbf{f}=\beta y \mathbf{z}$. The full gravity $g$ was decreased from 9.81 to $2.5 \mathrm{~m} \mathrm{~s}^{-2}$. This was found to reduce the amplitude of barotropic basin modes that were strongly excited with the larger value of $g$. This slows the barotropic gravity/Kelvin waves by a factor of 2 and the barotropic Rossby waves by a factor of 4 , but they each remain much faster than the baroclinic Rossby waves, which is the important feature to retain.

The model is configured in a rectangular domain extending from $y=-3 \times 10^{6} \mathrm{~m}$ to $y=6 \times 10^{6} \mathrm{~m}$, so that the model domain extends across the equator, as shown in Fig. 1. The zonal width of the domain is $6 \times 10^{6} \mathrm{~m}$. The grid spacing is $40 \mathrm{~km}$ with a lateral viscosity of $A=5 \times 10^{3} \mathrm{~m}^{2} \mathrm{~s}^{-1}$. At this resolution and viscosity the model is not eddy resolving, although instabilities do emerge for some parameter choices. The central calculation was compared with a run carried out at $10-\mathrm{km}$ resolution with reduced viscosity and the low-frequency behavior was nearly identical (discussed more below).

The boundary conditions on the eastern and western boundaries are no normal flow and no slip. The boundary conditions on the northern and southern boundaries are either closed with no normal flow and no slip, or they are open. For open boundaries, the layer thicknesses are 
specified at the northwest and southwest corners of the domain. This is equivalent to specifying the density along the western boundary at the poleward limits of the model domain and is consistent with information being propagated equatorward along the western boundary and thus determined by processes outside the model domain. Along the southern and northern boundaries, the interface thickness is specified by a profile $h_{k: n, s}^{*}$ that smoothly transitions from the average layer thickness along the boundary between $d=120 \mathrm{~km}$ and the eastern boundary $\bar{h}_{k: n, s}$ and the specified value at the northwest $\left(H_{k: \text { nw }}\right)$ or southwest $\left(H_{k: \mathrm{sw}}\right)$ corner:

$$
h_{k: n, s}^{*}=H_{k: \mathrm{nw}, \mathrm{sw}}+\left(\bar{h}_{k: n, s}-H_{k: \mathrm{nw}, \mathrm{sw}}\right) \tanh (x / d) .
$$

This smooths out the influence of mesoscale eddies and waves propagating along the northern boundary while still allowing the inflow/outflow to adjust to basin-scale changes to the interior pressure field.

The meridional velocity in each layer is restored toward values that are geostrophically balanced with this interface slope with a time scale of $3600 \mathrm{~s}$ within $300 \mathrm{~km}$ of the northern and southern boundaries. There is no net transport through either boundary; it is a purely baroclinic exchange. The model adjusts to changes in the layer thickness in the basin interior by increasing or decreasing the meridional transport through the boundary. The transport within each layer at the northern boundary does not need to be, and generally will not be, the same as the transport through the southern boundary. The width scale of the western boundary current $d$ and the meridional extent of the restoring region have been varied but the results are not overly sensitive to these parameters.

Specification of the layer thickness at the northwest and southwest corners of the domain results in a mean overturning circulation forced by water mass transformation outside the model domain of strength

$$
\Psi=0.25\left(H_{2 \mathrm{nw}}^{2}-H_{e}^{2}\right) g^{\prime} / f_{n},
$$

where $f_{n}$ is the Coriolis parameter at the northern latitude of the domain. The mean thickness of layer 2 along the eastern boundary $H_{e}$ is determined by balancing the mean meridional mass transport through the northern and southern boundaries:

$$
H_{e}=\left[\frac{H_{2 \mathrm{nw}}^{2}-\left(f_{n} / f_{s}\right) H_{2 \mathrm{sw}}^{2}}{1-f_{n} / f_{s}}\right]^{1 / 2},
$$

The Coriolis parameter at the southern boundary $f_{s}<0$. For $H_{2 \mathrm{nw}}>H_{2 \mathrm{sw}}$, this value of the lower layer thickness on the eastern boundary results in a mean transport into the lower layer from the north that is balanced by a transport out of the domain through the southern boundary. If the layer thickness on the eastern boundary is a function of time then the transport into or out of the domain will also vary in time, allowing for temporary isopycnal mass storage within the model domain.

The model is forced with a zonal wind stress curl pattern that drives midlatitude subtropical and subpolar gyres in the Northern Hemisphere. The absolute value of the wind stress is offset such that it goes to zero outside of the latitude range $y_{0}-L_{y}<y<y_{0}+L_{y}$ (Fig. 1). The wind stress is uniform in $x$ and varies in time with period $P$ :

$$
\begin{aligned}
\tau(y, t)= & \frac{1}{2} \tau_{0}\left[1+\cos \pi\left(y-y_{0}\right) / L_{y}\right](1+\alpha \sin 2 \pi t / P), \\
& y_{0}-L_{y}<y<y_{0}+L_{y} \\
\tau= & 0, \quad\left|y-y_{0}\right| \geq L_{y} .
\end{aligned}
$$

This idealized wind stress distribution has the advantage of isolating the Ekman transport to a confined region of the domain away from the northern and southern boundaries. As a result, the integrated Ekman pumping in the subtropical gyre is equal and opposite to that in the subpolar gyre. This provides some conceptual advantages, as outlined below, but also does not allow for asymmetric forcing anomalies as might arise if there were a net Ekman pumping in the domain. Such forcing would require a nonzero wind, and thus Ekman transport, at either the northern or southern boundary, which would need some special treatment in order to avoid unrealistic isopycnal displacements and subsequent along-boundary flows. Nonetheless, the mechanisms connecting the wind stress anomalies to the MOC variability are general and provide a useful framework for understanding the response to a wider range of forcing configurations.

The model is initialized at rest with layer thicknesses $H_{1}$ and $H_{2}$ and forced with the time-dependent wind stress until an equilibrium cycle is reached. Equilibration takes approximately 30 years, depending on the parameters of each calculation. For some runs the period of forcing is longer than this equilibration time scale, in which case the model is run for two forcing periods. The mean wind stress amplitude is $\tau_{0}=0.15 \mathrm{~N} \mathrm{~m}^{-2}$, and the amplitude for the temporal variability is $\alpha=1 / 3$. This provides a mean Sverdrup transport of $\Psi_{\mathrm{sv}}(x, y)=$ $\pi \tau_{0} x \sin \left[\pi\left(y-y_{0}\right) / L_{y}\right] / 2 \beta \rho_{0} L_{y}$, which, with $\beta=2 \times$ $10^{-11} \mathrm{~m}^{-1} \mathrm{~s}^{-1}, L_{y}=2 \times 10^{6} \mathrm{~m}$, and $y_{0}=3.5 \times 10^{6} \mathrm{~m}$, has a maximum amplitude of $34 \mathrm{~Sv}$ at the midlatitudes of the 

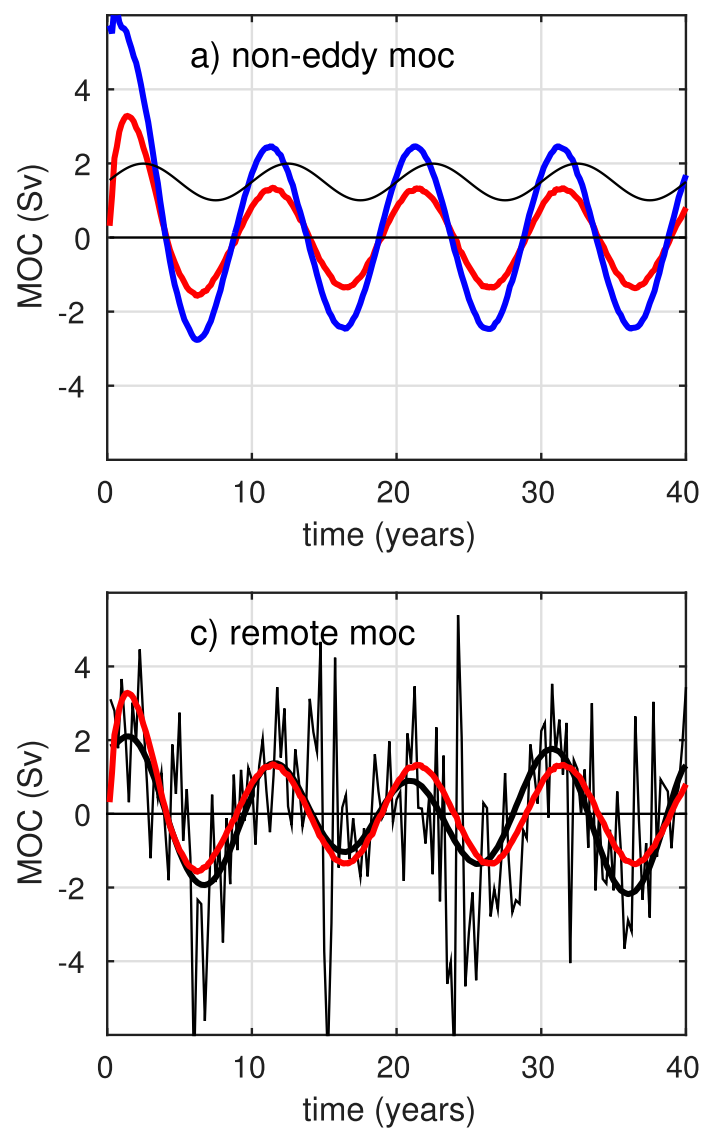

subtropical and subpolar gyres, close to that found in the numerical model (Fig. 1). The overturning circulation is defined as the net meridional transport in layer 2 at each latitude. Because surface displacements are very small, this is essentially balanced by an equal and opposite meridional transport in layer 1 . Overturning here is calculated in density space but does not reflect a diapycnal transformation within the model domain, although cases with open northern and southern boundaries implicitly assume a transformation takes place outside the domain.

\section{Closed basin: No mean MOC}

The wind-driven MOC variability is first considered in a closed domain that lacks a mean meridional flow in the lower layer. The influences of a mean MOC introduced through boundary conditions along the northern and southern boundaries will be considered in the following section.

\section{a. Blocked geostrophic contours}

Stratification parameters of $g^{\prime}=0.05 \mathrm{~m} \mathrm{~s}^{-2}$ and $H_{1}=H_{2}=600 \mathrm{~m}$ result in sufficiently weak interface

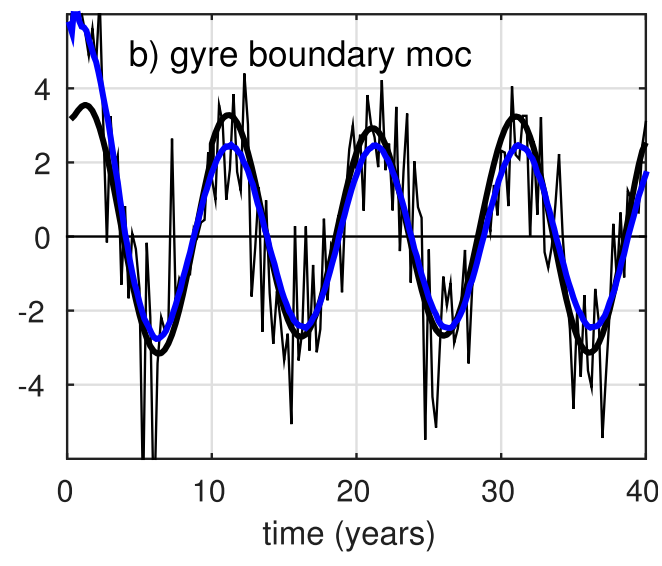

FIG. 2. Time series of the overturning circulation for (a) noneddy-resolving configuration at the gyre boundary ( $y=3500 \mathrm{~km}$, blue line) and at the southern boundary of the subtropical gyre $(y=1500 \mathrm{~km}$, red line) for a case with a forcing period of 10 years. The wind stress $\left(\mathrm{N} \mathrm{m}^{-2} \times 10\right)$ at $y=3500 \mathrm{~km}$ is given by the thin black line. (b) Overturning circulation at the gyre boundary for the noneddy-resolving calculation (blue) and eddy-resolving calculation (black). (c) Overturning at the southern boundary of the subtropical gyre for the noneddy-resolving calculation (red) and the eddy-resolving calculation (black). The black thin lines in (b) and (c) are at monthly output, and the black bold lines are bandpass filtered between 5- and 20-yr periods.

displacements that the geostrophic contours in the second layer, defined as contours of constant $f / h_{2}$, extend from the eastern boundary to the western boundary with no regions of closed contours. This is defined as the linear, or blocked, regime. As will be shown in the following subsection, larger interface displacements result in regions near the western boundary in which the geostrophic contours do not connect to the eastern boundary, which will be called the closed regime.

The overturning circulation strength using the central parameters with a forcing period of $P=10$ years is shown in Fig. 2a at the latitude of the gyre boundary $(y=$ $y_{0}$ ) and at the southern boundary of the subtropical gyre $\left(y=y_{0}-L_{y}\right)$. At the gyre boundary, the overturning oscillates with an amplitude of $2.5 \mathrm{~Sv}$, nearly in phase with the forcing. This range of wind-driven variability is similar to that observed at $26.5^{\circ} \mathrm{N}$ (Kanzow et al. 2010). The magnitude of the variability in the Ekman transport at the gyre boundary is $\Psi_{E}=\alpha \tau_{0} L / \rho_{0} \beta y_{0}=4.2 \mathrm{~Sv}$, where $L=6 \times 10^{6} \mathrm{~m}$ is the zonal width of the basin. For equal layer thicknesses, this produces an overturning amplitude of $2.1 \mathrm{~Sv}$. The larger overturning found here suggests that the response is more complex than a simple barotropic return flow. At the southern boundary of the 
subtropical gyre, where the wind stress and Ekman transport go to zero, the overturning circulation varies sinusoidally with an amplitude of $1.4 \mathrm{~Sv}$. If the overturning were simply related to the locally forced Ekman transport, then it would vanish at this latitude. The overturning circulation at the southern boundary of the subtropical gyre is the focal point of this study and will be referred to as the remotely forced overturning.

This calculation was repeated with a horizontal resolution of $10 \mathrm{~km}$ and a horizontal viscosity of $200 \mathrm{~m}^{2} \mathrm{~s}^{-1}$ to test the influence of mesoscale eddies and baroclinic instability on the low-frequency response to oscillations in the wind strength. The overturning circulation was diagnosed at both the gyre boundary and the southern limit of the subtropical gyre (Figs. 2b,c). Meoscale variability introduces strong high-frequency fluctuations to the overturning, at times even reversing the direction compared to the noneddy-resolving result, especially so for the remote overturning. However, when this time series is bandpass filtered for periods between 5 and 20 years, the low frequency response to variable winds is very close to that produced in the absence of eddies. From this it is concluded that mesoscale eddies are not responsible for the dominant physics controlling the low-frequency overturning response to variable winds. All calculations in the remainder of the paper are carried out on the noneddy-resolving $40-\mathrm{km}$ grid.

To further explore the dependence of the remotely forced overturning on forcing period, the model was run with the same physical parameters and with $P$ between 0.25 and 200 years. The magnitude of the overturning variability at each latitude is shown as a function of forcing frequency in Fig. 3. The overturning circulation has been scaled by the variability in the Ekman transport at the gyre boundary $\Psi_{E}$ and has been plotted against the nondimensional frequency $\Omega=L / \beta L_{d}^{2} P=T_{\mathrm{RW}} / P$, defined as the basin-crossing time scale for a baroclinic Rossby wave at the latitude of the gyre boundary divided by the forcing pe$\operatorname{riod} P$. The basin-crossing time scale $T_{\mathrm{RW}}=L / \beta L_{d}^{2}$ and the baroclinic deformation radius at this latitude is $L_{d}=\left[g^{\prime} H_{1} H_{2} /\left(H_{1}+H_{2}\right)\right]^{0.5} / \beta y_{0}$. At high frequencies the overturning scales with the variability in the Ekman transport and is confined within the latitude range of the wind stress anomalies. This is consistent with a local barotropic response to the meridional Ekman transport (Jayne and Marotzke 2001). At low frequencies the overturning is very weak. This is as expected because, for times longer than the basincrossing time scale, the upper layer is in equilibrium with the wind and the lower layer is at rest. For time scales close to the basin crossing time scale there is a strong remotely forced overturning that extends from

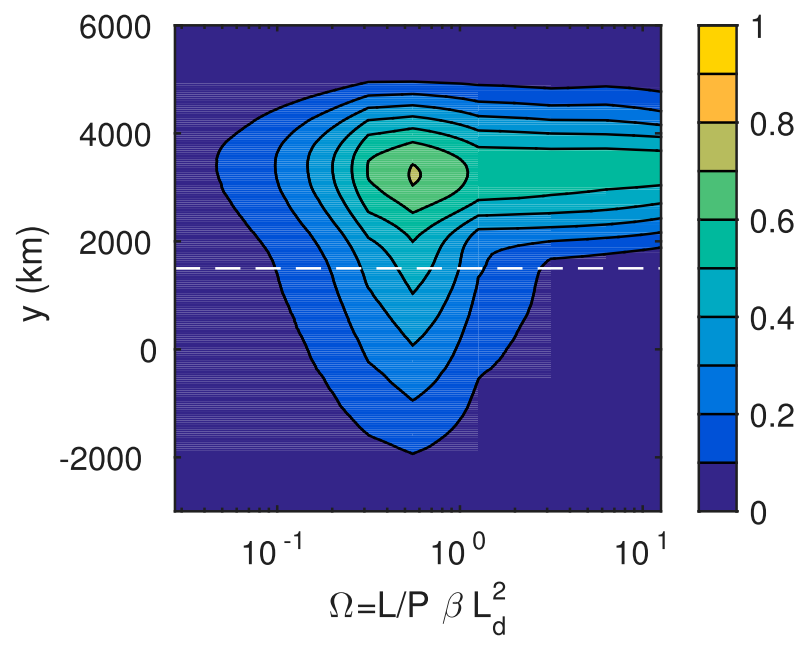

FIG. 3. Magnitude of the overturning variability, scaled by the Ekman transport variability, as a function of latitude and nondimensional forcing frequency for $g^{\prime}=0.05 \mathrm{~m} \mathrm{~s}^{-2}$. The white dashed line is the southern boundary of the subtropical gyre.

the southern limit of the subtropical gyre all the way into the Southern Hemisphere. There is a small enhancement within the gyres as well.

To demonstrate that this frequency/latitude dependence of the remotely forced overturning is persistent over a wide range of parameter space, the model has been run with forcing periods between 1 and 100 years with $g^{\prime}=0.0125,0.025,0.05 \mathrm{~m} \mathrm{~s}^{-2}$ and $\beta=1,2,4$, $6 \times 10^{-11} \mathrm{~m}^{-1} \mathrm{~s}^{-1}$, resulting in a total of 60 model runs. The magnitudes of the overturning circulation variability at the gyre boundary and at the southern boundary of the subtropical gyre are shown in Fig. 4a as a function of forcing frequency. The magnitude of the overturning circulation variability ranges in value from approximately 0.1 to over $5 \mathrm{~Sv}$, while the maximum remotely forced overturning variability approaches $3 \mathrm{~Sv}$. The central calculation is indicated in Fig. 4 a by green squares. The overturning circulation scaled by the Ekman transport variability and plotted as a function of the nondimensional forcing frequency $\Omega=T_{\mathrm{RW}} / P$ is shown in Fig. 4b. The data points nearly collapse onto two curves. The overturning circulation variability at the gyre boundary scales with the barotropic response at high frequencies, slightly exceeds the barotropic response near $\Omega=1 / 2$, and drops off rapidly at low frequencies. The remotely forced overturning shows a peak near $\Omega=1 / 2$ and drops off at both high and low frequencies, similar to the results for the central case in Fig. 3.

The mechanism for forcing the remote overturning circulation can be understood by considering the mass budget within the wind-forced gyres. For the winds used here, the Ekman pumping integrated over the subtropical 

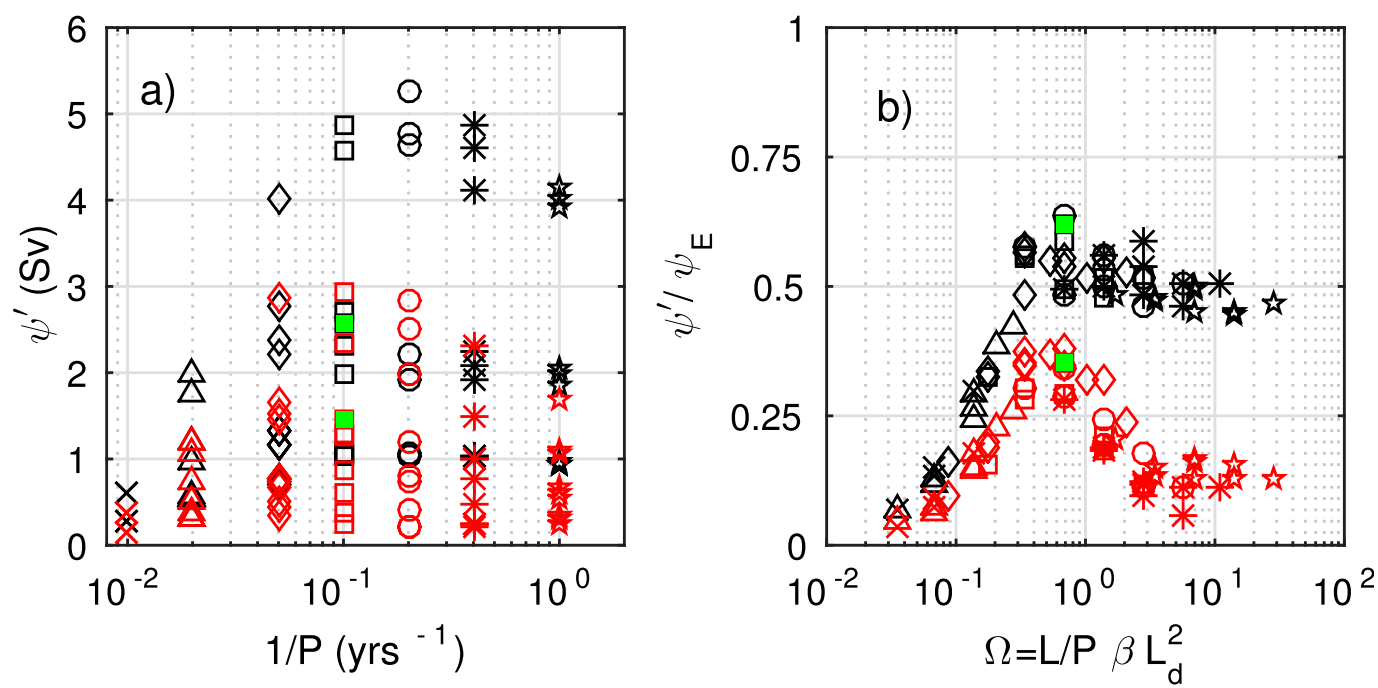

FIG. 4. A scatterplot of the diagnosed amplitude of the variability in the overturning circulation as a function of forcing period for various values of $\beta$ and $g^{\prime}$. (a) Dimensional (Sv) and (b) transport scaled by the Ekman transport variability and period scaled by the Rossby wave basin crossing time scale. Black symbols are at the latitude of the gyre boundary, and red symbols are at the southern boundary of the subtropical gyre. The symbols identify the dimensional forcing period, as indicated in (a). The green squares are for the run in Fig. 2.

gyre is of equal magnitude and opposite sign to the integrated Ekman pumping over the subpolar gyre at all times and forcing frequencies. At high forcing frequencies the change in upper layer thickness within the subtropical gyre is of equal magnitude and opposite sign to the change in layer thickness within the subpolar gyre at all times. There is a mass exchange between gyres carried by the Ekman transport and balanced by return barotropic flow in both layers (Jayne and Marotzke 2001).

The horizontal circulation response to this Ekman pumping within each of the gyres is barotropic at high frequencies. However, as the forcing anomaly persists for longer time periods, the circulation adjusts and the wind-driven flow is carried more and more by the upper layer. This transition from barotropic to baroclinic flow occurs in this two layer model as the mode- 1 baroclinic Rossby wave propagates from the eastern boundary toward the west (Anderson and Gill 1975). Because Rossby waves propagate more slowly with increasing latitude, the subtropical gyre equilibrates faster than does the subpolar gyre. As a result, the interface displacement in the subpolar gyre will be larger than it is in the subtropical gyre subject to the same Ekman pumping anomaly. This is consistent with the equilibrium state in which the change in layer thickness away from the eastern boundary in the subpolar gyre must be larger (and of opposite sign) compared to that in the subtropical gyre in order to balance the same Sverdrup transport (because the Coriolis parameter is larger at higher latitudes).
This is reflected in the mean thickness of layer 2 for the case with a 10-yr forcing period (Fig. 5a). The interface displacement in the subpolar gyre is much larger than that in the subtropical gyre, but it is not enough to close the mean potential vorticity contours in layer 2 (Fig. 5b). Although there is some deflection from constant latitude circles, all of the potential vorticity contours extend from the eastern boundary to the western boundary. The change in the lower layer thickness experienced over a forcing period $\delta h_{2}$ is much larger in the subpolar gyre than it is in the subtropical gyre (Fig. 5c). The phase at which the maximum layer thickness is found shows rapid equilibration in the subtropical gyre, with maximum thickness found just after the winds are the weakest (Fig. 5d). The basin-crossing time scale at the midlatitude of the subtropical gyre is about 2 years, much less than the forcing period of 10 years. At the midlatitude of the subpolar gyre the basincrossing time scale is about 6 years, roughly one-half the forcing period. The phase of maximum layer thickness in the subpolar gyre reflects this basincrossing time scale with a maximum thickness on the western boundary at roughly $180^{\circ}$, or just when the forcing anomaly changes sign.

It is useful to consider the interface displacement that would arise if the Sverdrup transport were carried entirely in the upper layer, as expected for the linear solution of baroclinic flow at forcing periods longer than the basin-crossing time scale. Integrating the geostrophic transport yields 

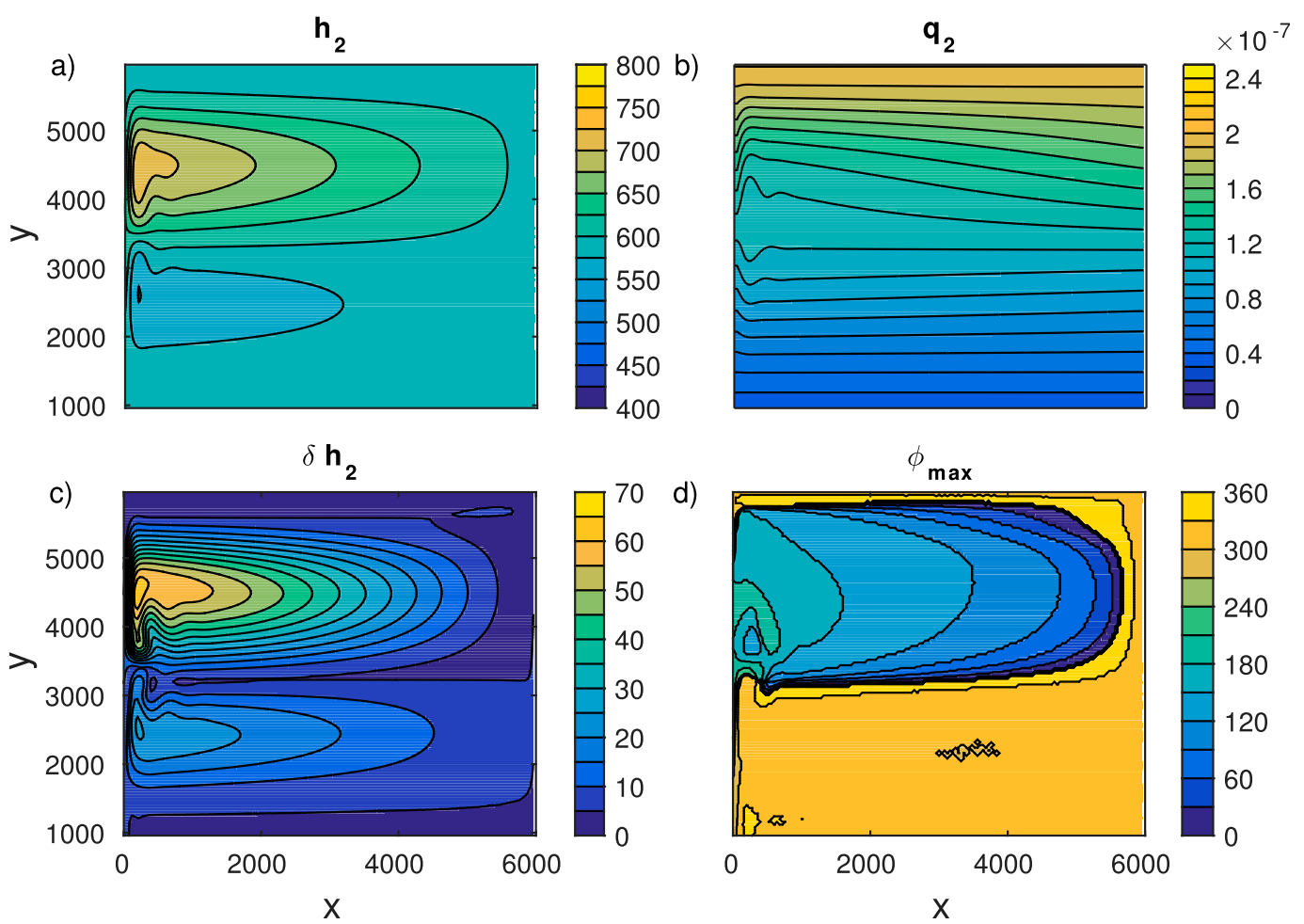

FIG. 5. (a) Mean thickness of layer $2(\mathrm{~m})$ for $g^{\prime}=0.05 \mathrm{~m} \mathrm{~s}^{-2}$ and a forcing period of 10 years; (b) mean potential vorticity layer $2\left(\mathrm{~m}^{-1} \mathrm{~s}^{-1}\right)$; (c) maximum minus minimum in layer 2 thickness $(\mathrm{m})$ over a forcing period; and (d) phase at which layer 2 attains its maximum thickness. The wind stress is a maximum at $90^{\circ}$ phase and a minimum at $270^{\circ}$ phase.

$$
h(x, y)=\left[h_{1 e}^{2}+\Psi_{\mathrm{sv}} \beta y / g^{\prime}\right]^{1 / 2} \approx h_{1 e}+0.5 \Psi_{\mathrm{sv}} \beta y / g^{\prime} h_{1 e} .
$$

The approximation on the right hand side is valid in the limit $\Psi_{\mathrm{sv}} \beta y / g^{\prime} h_{1 e}^{2} \ll 1$, which is equivalent to the interface displacement across the basin being small compared to $h_{1 e}$, the thickness of the upper layer on the eastern boundary. One can see that the interface displacement will be larger in the subpolar gyre than in the subtropical gyre because the interface displacement is proportional to $y$. If both gyres are to remain in thermal wind balance in that portion of the domain where the baroclinic Rossby wave emanating from the eastern boundary has passed, then the subpolar gyre draws or expels more fluid than can be provided or accommodated by the subtropical gyre. Therefore, this mass must be supplied from latitudes to the south of the subtropical gyre via the western boundary current. This is the essential driving mechanism for the remotely forced meridional overturning circulation.

A simple heuristic model for the remotely forced overturning is now developed that explains the basic parameter dependencies found in the numerical model. The remotely forced overturning transport can be interpreted as the time rate of change of the difference in the volume required to maintain geostrophic balance in the subpolar gyre compared to that required in the subtropical gyre. First consider a forcing period that is long compared to the Rossby wave basin-crossing time scale. The change in the volume of layer 1 scales as the integral over the subtropical and subpolar gyres of the layer thickness at the maximum wind stress $h^{+}(x, y)$ minus the integral of the layer thickness at the minimum wind stress $h^{-}(x, y)$. Making use of the approximate solution in (8), this is

$$
\delta V=\int_{x_{e}}^{L} \int_{y_{0}-L_{y}}^{y_{0}+L_{y}} h^{+}(x, y)-h^{-}(x, y) d y d x \approx \frac{\alpha \tau_{0} L_{y} L^{2}}{\rho_{0} g^{\prime} h_{1 e}} .
$$

For forcing periods longer than the basin-crossing time scale, this total change in volume is $\delta V$ and takes place over one-half the forcing period. Assuming sinusoidal variability in time, the maximum/minimum transport is a factor of $\pi / 2$ larger than this average transport:

$$
\Psi=\frac{\pi}{2} \frac{\delta V}{P / 2}=\frac{\pi}{P} \frac{\alpha \tau_{0} L_{y} L^{2}}{\rho_{0} g^{\prime} h_{1 e}}
$$


The maximum overturning $\Psi_{\max }$ will be found when $P=2 T_{\mathrm{RW}}$. This can be scaled with the Ekman transport at the gyre boundary $\Psi_{E}$ to clarify the underlying parameter dependence:

$$
\frac{\Psi_{\max }}{\Psi_{E}}=\frac{\pi L_{y} H_{2}}{2 y_{0}\left(H_{1}+H_{2}\right)} \approx \frac{\pi L_{y}}{4 y_{0}},
$$

where it has been assumed that $h_{1 e}=H_{1}$. This scaling predicts that the maximum remotely forced overturning depends on the meridional scale over which the winds vary, $L_{y}$, relative to the latitude of the gyre boundary $y_{0}$. Assuming equal layer thicknesses, these are the only parameters that control the relative strength of the remote overturning. For spatial variations in the wind stress anomalies on small scales, the remote overturning is weak because the temporal changes in volume are small. Increasing the latitude of the gyre boundary (increasing $y_{0}$ ) decreases the overturning because the increase in the adjustment time (proportional to $y_{0}^{2}$ ) outweighs the reduced strength of the Ekman transport (which is proportional to $y_{0}^{-1}$ ). This scaling explains why the model results in Fig. 4b show approximately the same nondimensional strength of remote overturning for a wide range of $\beta, g^{\prime}$, and $P$. This scaling is supported by a series of numerical model calculations in which $L_{y}$ and $y_{0}$ were varied (Fig. 6).

The expression for $\delta V$ is the maximum possible volume anomaly generated by the changing midlatitude winds. At low frequencies this change in volume takes place over one-half the forcing period. At forcing periods shorter than twice the basin-crossing time scale the Rossby wave has not propagated all the way across the basin before the wind anomalies change sign. For zonally uniform winds, the fraction of the change in volume anticipated by the equilibrium solution scales linearly with the forcing period relative to the basin-crossing time scale. These time factors can be compactly written together with $\delta V$ to represent the strength of the remotely forced overturning $\Psi_{R}$ as a function of forcing period as

$$
\Psi_{R}=\frac{\pi \delta V}{2} \frac{\min \left(0.5 P / T_{\mathrm{RW}}, 1\right)}{\max \left(0.5 P, T_{\mathrm{RW}}\right)} .
$$

The theory (12), scaled with $\Psi_{E}$, produces a maximum overturning of approximately 0.45 at a forcing period twice the basin-crossing time scale (Fig. 7a). The amplitude decays as $T_{\mathrm{RW}} / P$ for $\Omega<.5$, and it decays as $P / T_{\mathrm{RW}}$ for $\Omega>$.5. The overturning diagnosed from the model at the southern boundary of the subtropical gyre is indicated by the red curve in Fig. 7a, and the overall agreement in terms of magnitude and frequency dependence is quite good.

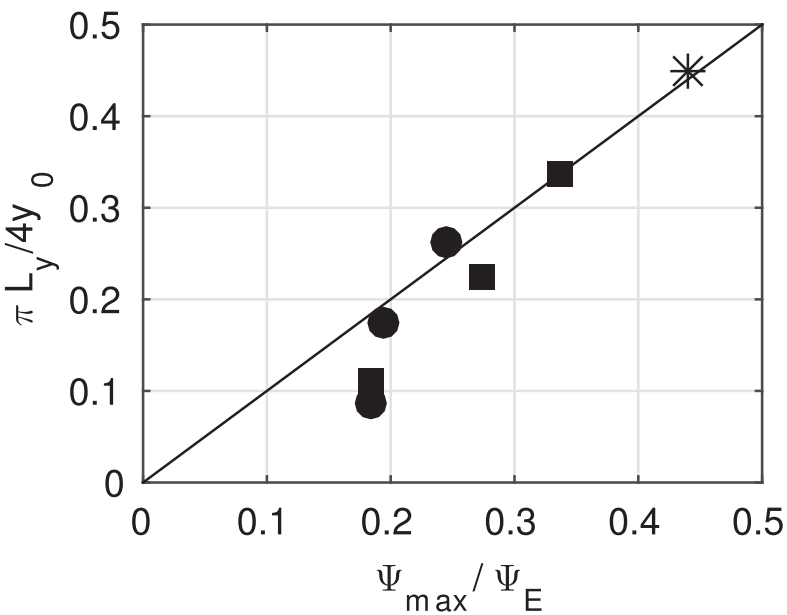

FIG. 6. Comparison of the variability in remote overturning strength scaled by the variability in Ekman transport diagnosed from a series of model runs with the scaling estimate (11). The symbols mark runs in which $L_{y}$ is varied and $y_{0}=3.5 \times 10^{6} \mathrm{~m}$ (squares) and $y_{0}=4.5 \times 10^{6} \mathrm{~m}$ (circles). The asterisk marks the central calculation with $L_{y}=2 \times 10^{6} \mathrm{~m}$ and $y_{0}=3.5 \times 10^{6} \mathrm{~m}$.

The variability of the meridional transport, zonally and cumulatively integrated from $x=0$, as a function of longitude and frequency shows that this anomalous transport can take place in the interior or near the western boundary. The longitude where the variability in the meridional transport takes place is indicated by regions of strong zonal gradients. At the gyre boundary, most of the transport variability occurs in the basin interior (Fig. 8a). At high forcing frequencies (large $\Omega$ ) it is nearly uniform in longitude, consistent with the expected barotropic response to Ekman transport in the interior. As the frequency decreases the variability shifts slightly to the west until the basin-crossing time scale $(\Omega \approx 1)$ is approached. At this point the magnitude of the overturning increases and it takes place mostly in the western and central basin. There is a slightly out of phase transport near the eastern boundary near the basincrossing time scale (where the magnitude of the variability decreases). At low frequencies the variability in overturning shifts toward the west and decreases in amplitude.

South of the subtropical gyre, but still in the Northern Hemisphere, the variance is concentrated along the western boundary at moderate to low frequencies (Fig. 8b) with only very weak variability at high frequencies. There is again a weak out of phase meridional transport in the interior, now extending farther toward the west than was found at the gyre boundary. This weakening variance in the eastern basin, as well as that found at the gyre boundary, is the signal of westward propagating thickness anomalies that are out of phase 

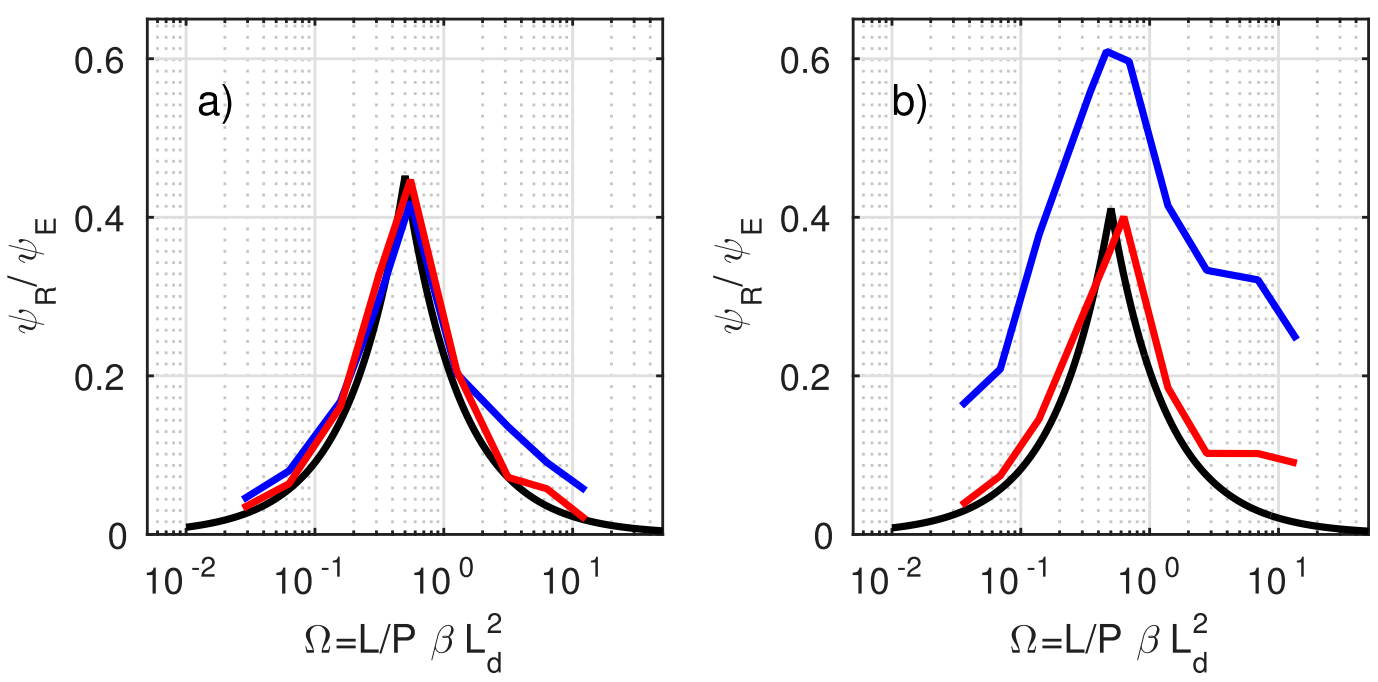

FIG. 7. The magnitude of the remotely forced overturning variability (at the southern boundary of the subtropical gyre) as a function of nondimensional forcing frequency. Black: theory given by (12) with (9); red: numerical model with closed north/south boundaries; blue: numerical model with a mean overturning circulation of $12.5 \mathrm{~Sv}$. (a) Blocked geostrophic contours $\left(g^{\prime}=0.05 \mathrm{~m} \mathrm{~s}^{-2}, H_{2}=600 \mathrm{~m}\right)$; (b) closed geostrophic contours $\left(g^{\prime}=0.025 \mathrm{~m} \mathrm{~s}^{-2}\right.$, $\left.H_{2}=500 \mathrm{~m}\right)$.

with the thickness anomalies in the interior of the basin. This reverse meridional transport is most important at intermediate frequencies, at sufficiently low frequencies the waves have crossed the basin and shut down the meridional transport anomaly.

In the Southern Hemisphere the anomalous meridional transport is carried in the basin interior (Fig. 8c). This is the same magnitude as the out of phase interior transport in the Northern Hemisphere at $1000-\mathrm{km}$ latitude. It is concentrated near the midlatitude basincrossing time scale because it is forced by the Northern Hemisphere midlatitude mass imbalance.

\section{b. Closed geostrophic contours}

The simple theory derived above is based on the adjustment within the subtropical and subpolar gyres to changes in wind stress by the propagation of baroclinic Rossby waves along latitude circles. However, if the interface displacement is sufficiently large, there will be a region near the western boundary where the geostrophic contours do not connect to the eastern boundary (Rhines and Young 1982; Young and Rhines 1982). This effectively blocks these regions from information propagating from the east and so we can expect the adjustment process might be different from the cases with no closed contours.

Decreasing the value of $g^{\prime}$ to $0.025 \mathrm{~m} \mathrm{~s}^{-2}$ and reducing $\mathrm{H}_{2}$ to $500 \mathrm{~m}$ produces larger interface displacements and a region of closed potential vorticity contours in the western subpolar gyre, compare Fig. 9 with Fig. 5. Nonetheless, the overall structure and amplitude of the overturning variability is similar to that found in the previous section (Fig. 10a). The interface displacement scales inversely with $g^{\prime}$ from (9), but the time over which this change in volume takes place also scales inversely with $g^{\prime}$ so the variability of the overturning circulation remains nearly the same as found for $g^{\prime}=0.05 \mathrm{~m} \mathrm{~s}^{-2}$.

Figure $9 \mathrm{c}$ shows that the variability in interface displacement is maximum in the middle of the subpolar gyre, consistent with the slower Rossby wave speed resulting from the reduction in $g^{\prime}$. The steering of the Rossby waves around the closed potential vorticity contours is evident from the region within the closed contours with reduced variability of the interface. The phase of maximum layer thickness in Fig. 9d indicates these different regimes. In the eastern basin the wave propagates slowly while to the north of the closed contours, where the meridional gradient in potential vorticity is enhanced, the wave propagation speed increases. Within the closed contours the sense of propagation is eastward along the southern rim of the closed contours and westward along the northern rim. Because potential vorticity is a minimum in the center of the region, this cyclonic sense of propagation is to the left of the mean potential vorticity gradient along the mean potential vorticity contours. Although the details appear to differ, the time scale of adjustment in the region of closed potential vorticity contours is similar to that in the region of blocked contours. Because this time scale is similar, and the volume within the closed contours is relatively small compared to the volume of the subtropical and subpolar gyres, the linear theory (12) still 
a)

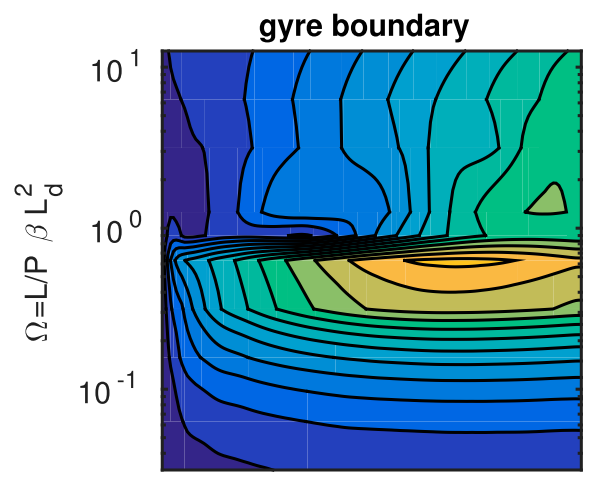

b)

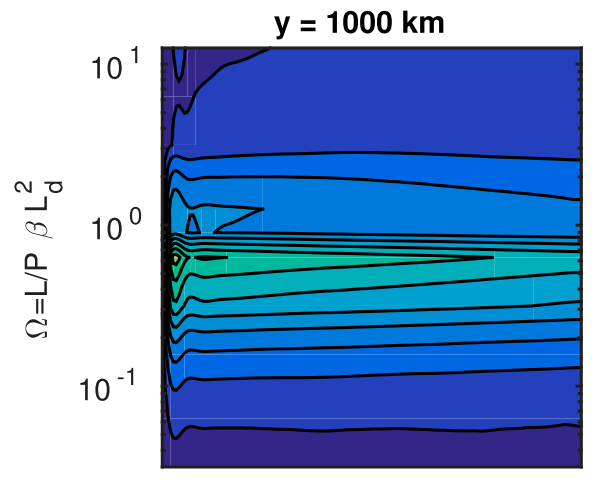

c)

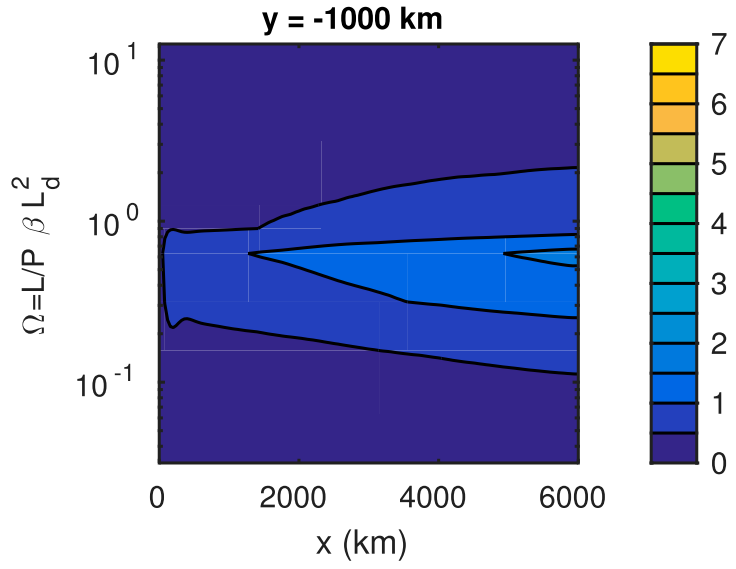

FIG. 8. Variability of the overturning circulation $(\mathrm{Sv})$ as a function of nondimensional frequency and distance from the western boundary at three different latitudes: (a) at the gyre boundary $(y=3500 \mathrm{~km})$; (b) south of the subtropical gyre and north of the equator $(y=1000 \mathrm{~km})$; and (c) south of the equator $(y=-1000 \mathrm{~km})$.

provides an accurate estimate of the remotely forced overturning circulation (Fig. 7b).

\section{Open basin: With mean MOC}

\section{a. Blocked geostrophic contours}

A mean overturning circulation was introduced, as represented by (4) with the layer thicknesses at the northwest and southwest corners to be $H_{2 \mathrm{nw}}=675 \mathrm{~m}$ and $H_{2 \mathrm{sw}}=525 \mathrm{~m}$. Using (5) and (6), with $g^{\prime}=0.05 \mathrm{~m} \mathrm{~s}^{-2}$, gives a mean overturning strength of $12.5 \mathrm{~Sv}$ and a mean layer thickness on the eastern boundary of $580 \mathrm{~m}$. The model was run at each of the same frequencies as for the closed basin. The overturning variability as a function of frequency and latitude is very similar to that produced with closed northern and southern boundaries in Fig. 3 (not shown). The magnitude of the remotely forced overturning is indicated in Fig. 7a by the blue line. It is very close to that found for the closed basin, with just slightly higher variance at high frequencies. Because the deep western boundary current (DWBC) remains along the western boundary, it does not interact with the winddriven gyres. There is also very little time dependence in the strength of the exchange through the northern boundary, indicating that the variability of the MOC is dominated by thickness variations along the western boundary that propagate equatorward in the Northern Hemisphere and not by thickness variations on the eastern boundary, which would drive variability in transport through the northern and southern boundaries.

\section{b. Closed geostropic contours}

Unlike in the blocked potential vorticity contour regime, with closed potential vorticity contours the presence of a mean overturning circulation significantly enhances the variability of the overturning in response to variable winds. The mean overturning of $12.5 \mathrm{~Sv}$ was introduced through the northern and southern boundaries for the case with $g^{\prime}=0.025 \mathrm{~m} \mathrm{~s}^{-2}$ by specifying $H_{2 \mathrm{nw}}=750 \mathrm{~m}$ and $H_{2 \mathrm{sw}}=450 \mathrm{~m}$. This gives a mean deep layer thickness on the eastern boundary of $570 \mathrm{~m}$, similar to the previous cases. The amplitude of the overturning circulation is shown as a function of latitude and frequency in Fig. 10b. The presence of the mean overturning circulation enhances the variability at all latitudes and frequencies compared to the case with no DWBC.

The reason for this increase in variability is that the deep western boundary current does not remain on the western boundary, it diverts into the interior north of the gyre boundary (Fig. 11a). Such an offshore diversion of DWBC water near the gyre boundary is consistent with observations (Hogg and Stommel 1985; Pickart and Smethie 1993). The leading empirical orthogonal function (EOF) of the layer 2 transport streamfunction, which explains $94 \%$ of the variance, is shown in Fig. 11 b. It is dominated by the spinup and spindown of the subtropical and subpolar gyres. The variability of the deep transport in the subpolar gyre is larger than in the subtropical gyre, consistent with the slower Rossby wave 

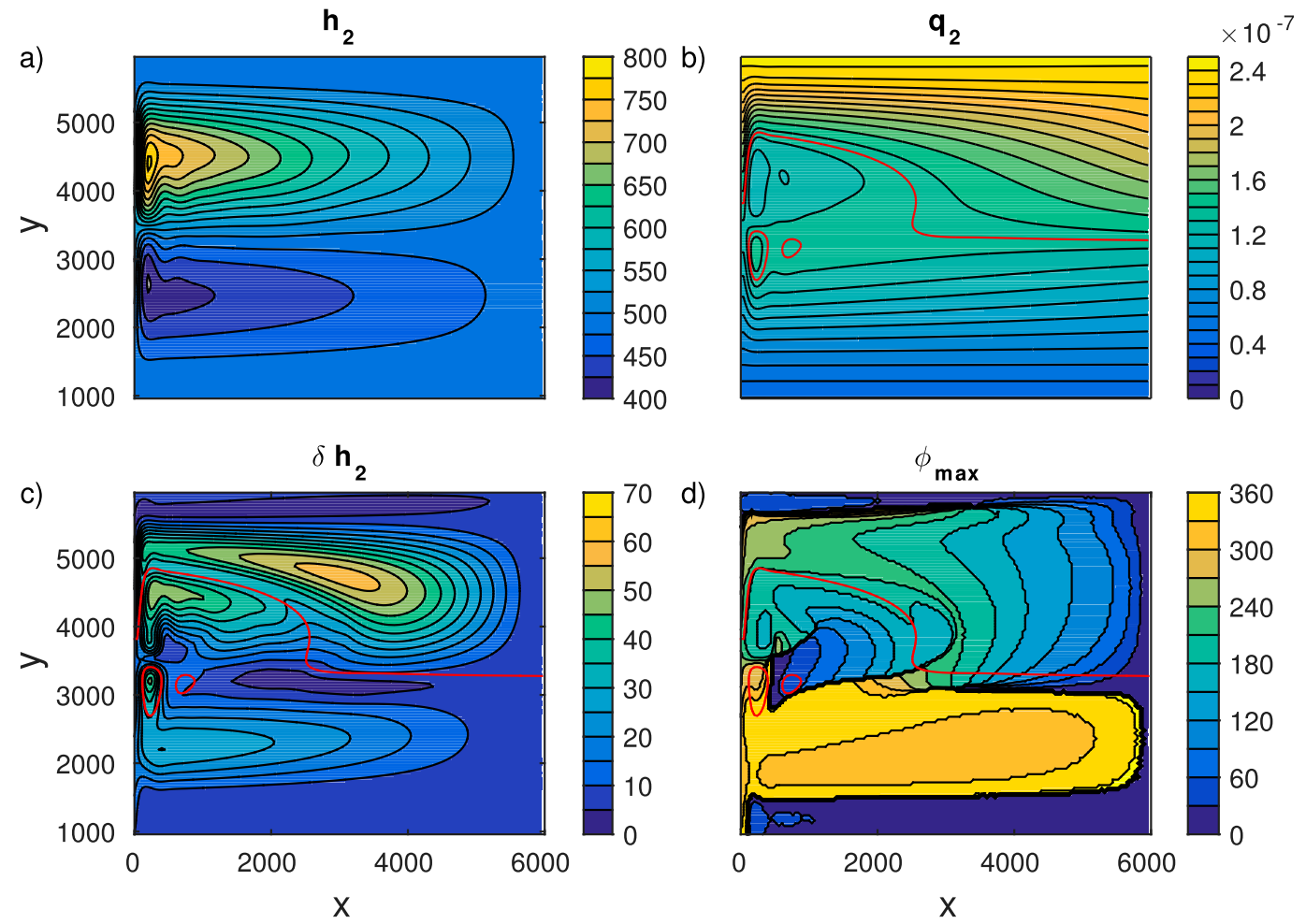

FIG. 9. As in Fig. 5, but with $g^{\prime}=0.025 \mathrm{~m} \mathrm{~s}^{-2}$. The red contour indicates the approximate boundary between the blocked potential vorticity contours in the east and the closed potential vorticity contours in the west.

speed and longer equilibration time. The modulation of the deep circulation is illustrated by the subtraction and addition of one EOF to the mean transport streamfunction. When the EOF is in the negative phase, the DWBC has weaker interior circulation and remains closer to the western boundary. In the positive phase, the DWBC penetrates farther into the basin and occupies a larger portion of the interior. A portion of the DWBC separates from the western boundary at the northern limit of the subpolar gyre and flows anticyclonically
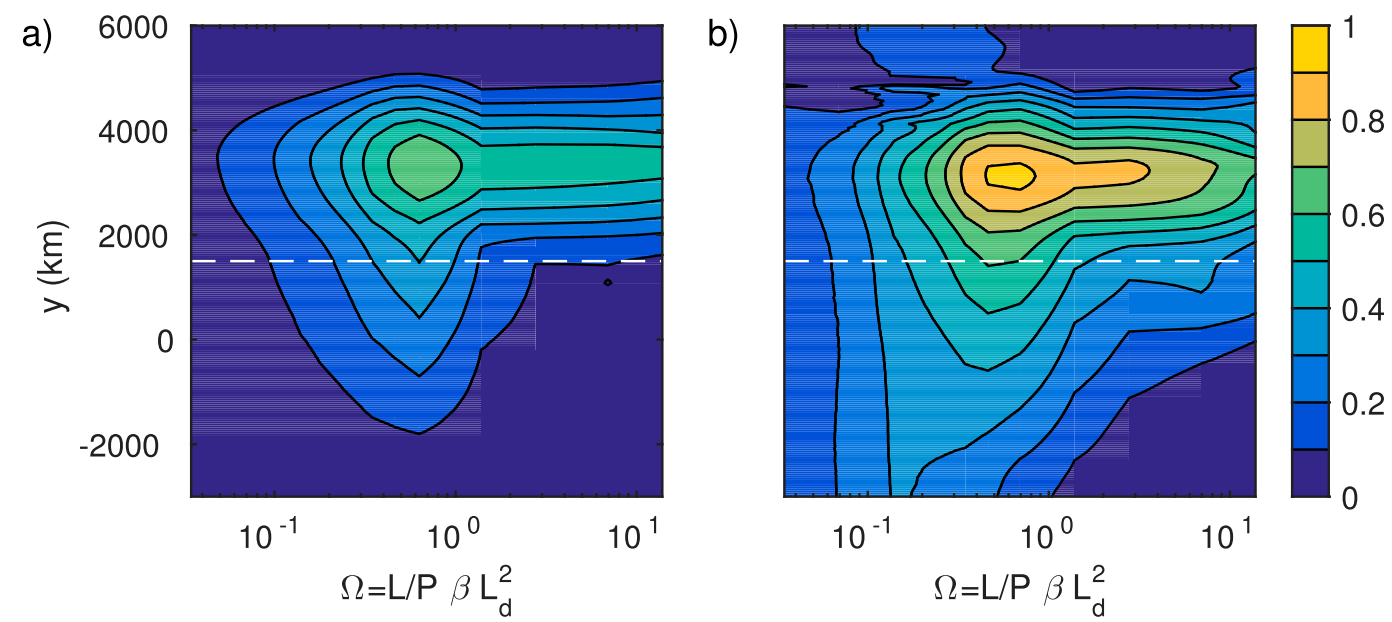

FIG. 10. (a) Magnitude of the overturning variability, scaled by the Ekman transport variability, as a function of latitude and nondimensional forcing frequency for $g^{\prime}=0.025 \mathrm{~m} \mathrm{~s}^{-2}, H_{2}=500 \mathrm{~m}$. The white dashed line is the southern boundary of the subtropical gyre. (a) No mean MOC; (b) 12.5-Sv mean MOC. 

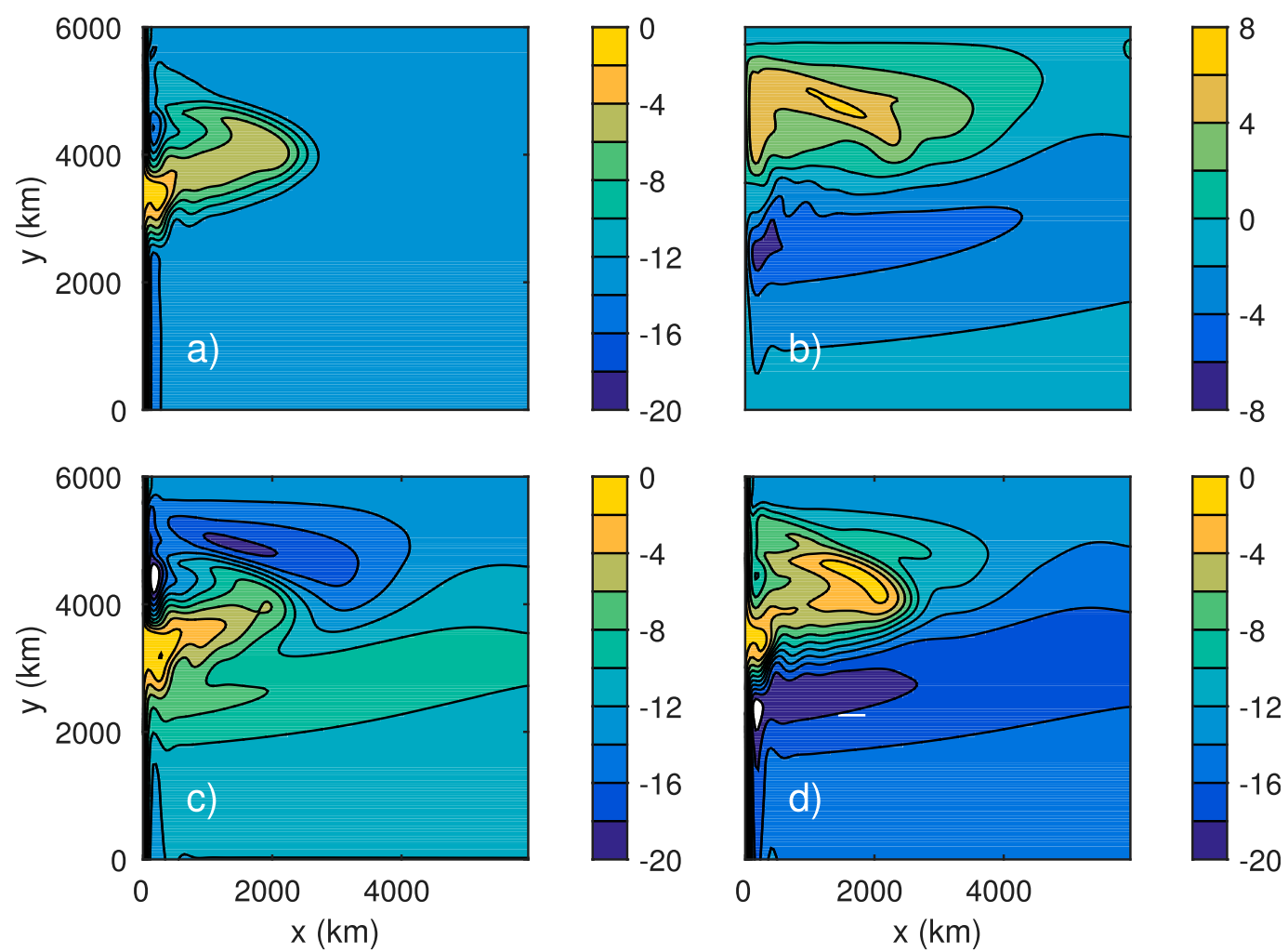

FIG. 11. (a) Mean transport streamfunction in layer $2(\mathrm{~Sv})$ for the calculation with $g^{\prime}=0.025 \mathrm{~m} \mathrm{~s}^{-2}$, forcing period of 10 years, and a mean overturning circulation of $12.5 \mathrm{~Sv}$. (b) Leading EOF for the layer 2 streamfunction (Sv), (c) mean transport streamfunction minus leading EOF (Sv), and (d) mean transport streamfunction plus leading $\mathrm{EOF}(\mathrm{Sv})$.

beneath the cyclonic upper layer wind-driven gyre, as has been observed by floats (Bower et al. 2009, 2011). Under strong winds the region expands and under weak winds the region contracts. This leads to a switching of the pathway for the deep western boundary current between along the boundary and into the interior.

The flow of DWBC water into the interior results in a decrease in the potential vorticity in the region of closed geostrophic contours compared to the case with no DWBC. Because the DWBC has a southward transport along the eastern edge of the recirculation, in the subpolar gyre where the wind-driven transport is northward, the baroclinic shear is enhanced. This results in a steeper gradient in both the thickness and potential vorticity of layer 2 (Figs. 12a,b). It is expected that this would result in enhanced baroclinic instability and eddy fluxes, but this is not resolved in the present model. The change in layer volume that results from variable winds in the region of closed potential vorticity contours is comparable to the change of volume in the region of blocked potential vorticity contours (Fig. 12c). This causes an increase or decrease of export of mass in the deep western boundary current that is in addition to the heaving of the thermocline as a direct result of variations in the wind stress curl.

\section{Conclusions}

The midlatitude Atlantic meridional overturning circulation (AMOC) varies on time scales of weeks to decades. Recent observational and modeling studies have demonstrated that much of the observed variability at $26.5^{\circ} \mathrm{N}$ can be attributed to wind stress, both at this latitude and farther north in the subpolar gyre (Kanzow et al. 2010; Zhao and Johns 2014a,b; Williams et al. 2014; Yang 2015; Pillar et al. 2016; Evans et al. 2017). The present study sheds light on how winds are able to force variability in the meridional overturning circulation with particular emphasis on the connection between midlatitude winds and low-latitude AMOC.

Idealized numerical model calculations show that AMOC variability is in direct response to local wind stress variability at periods shorter than the time it takes a baroclinic Rossby wave to cross the basin. At wind forcing periods longer than this, the AMOC decreases 

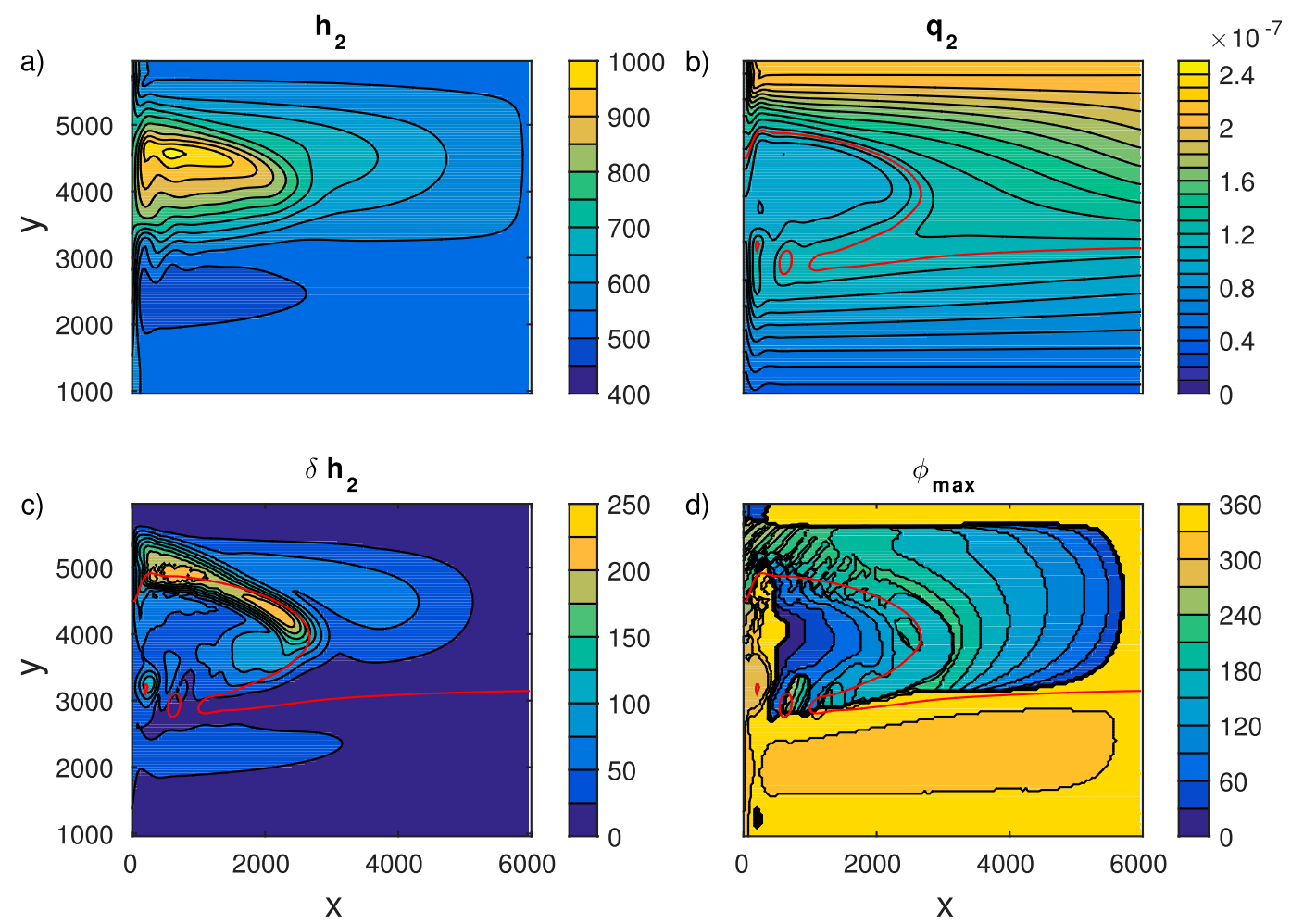

FIG. 12. As in Fig. 5, but with $g^{\prime}=0.025 \mathrm{~m} \mathrm{~s}^{-2}$ and a mean overturning circulation of $12.5 \mathrm{~Sv}$. The red contour indicates the approximate boundary between the blocked potential vorticity contours in the east and the closed potential vorticity contours in the west.

roughly inversely with the forcing period. This decay is a result of the transition to equilibration of the Sverdrup flow taking place over a longer time. A remotely forced component to the AMOC arises for forcing periods near the basin-crossing time scale. A simple heuristic theory was developed that predicts the amplitude and frequency dependence of this remote AMOC when compared to results from a series of numerical model runs. Its strength, relative to the variability in Ekman transport, depends primarily on the ratio of the meridional length scale of the wind variability to the latitude of the wind stress anomaly.

For the symmetric wind stress anomalies used here, the remote AMOC arises as a result of the different equilibration time scales between the subtropical and subpolar gyres. Rossby waves are faster at lower latitudes so the subtropical gyre adjusts to wind anomalies more quickly than does the subpolar gyre. Because the Coriolis parameter is larger at higher latitudes, the change in the volume of the upper and lower layers in response to the same changing winds is larger in the subpolar gyre than it is in the subtropical gyre. This volume surplus/deficit is imported from or exported to the rest of the basin south of the subtropical gyre in the western boundary current. There is nothing special about the southern limit of the subtropical gyre except that applying the mass budget to the entire region subject to anomalous winds provides a simple analytic solution and a clear connection between midlatitude winds and a remote response. Enhanced overturning is also found at midlatitudes due to the same imbalance in adjustment time scales.

For weak mean interface displacements the presence of a mean deep western boundary current does not influence the variability. However, for strong mean interface displacements a mean deep western boundary current can enhance the variability of the AMOC at all frequencies and latitudes over that predicted by this simple wave adjustment mechanism. This results from a diversion of the mean DWBC into the basin interior, where DWBC fluid can be stored and flushed on the forcing time scale.

The simple numerical model used here does not represent several processes that may be important for the wind-forced overturning circulation. The layer representation does not distinguish between the Ekman transport, which should be confined to the Ekman layer, and the geostrophic transport in the thermocline. We have chosen to consider only adiabatic flows but 
diapycnal mixing might serve to connect the upper and lower limbs of the MOC. It also does not allow for continuous stratification or better resolved vertical shear in the horizontal velocity fields. Wind-driven subduction and obduction are also not included as layer outcrops are not permitted in the model. Higher vertical resolution would also allow for additional baroclinic modes and a more refined adjustment to varying winds. Finally, baroclinic instability, which is not resolved in these calculations, might alter the MOC through eddy thickness fluxes.

There are a number of physical processes that may alter or add to the dynamics considered here. At high latitudes, where the stratification is weak, baroclinic Rossby waves become very slow and bottom topography can become more important so that the simple Sverdrup theory used here may not be valid. If the isopycnals outcrop, this will also weaken the predicted response as the wind stress would go directly into the deeper layers and limit the deflection of the interface. Bottom topography can also act as a waveguide and scattering mechanism for Rossby waves, which would alter their pathways and modify the spinup compared to the mode-1 waves propagating along zonal geostrophic contours considered here.

However, the underlying mechanism for connecting low-latitude variability of the meridional overturning circulation to wind stress anomalies at midlatitudes is the dual condition of satisfying geostrophy and of spatially varying adjustments to wind stress curl anomalies. This spatial variability may arise due to the slower propagation of Rossby waves at high latitudes, as in the cases discussed here, or it may be due to a net Ekman pumping anomaly. In either case, it is the resulting imbalances in the midlatitude mass budget that drives anomalies in the remote meridional overturning circulation.

Acknowledgments. MAS and DN were supported by the National Science Foundation under Grant OCE-1634468.

\section{REFERENCES}

Anderson, D. L. T., and A. Gill, 1975: Spin-up of a stratified ocean, with applications to upwelling. Deep-Sea Res., 22, 583-596, https://doi.org/10.1016/0011-7471(75)90046-7.

Bower, A. S., M. S. Lozier, S. F. Gary, and C. W. Böning, 2009: Interior pathways of the North Atlantic meridional overturning circulation. Nature, 459, 243-247, https://doi.org/10.1038/ nature 07979 .

,-- , and — 2011: Export of Labrador Sea water from the subpolar North Atlantic: A Lagrangian perspective. Deep-Sea Res. II, 58, 1798-1818, https://doi.org/10.1016/J.DSR2.2010.10.060.
Bryan, K., 1982: Seasonal variation in meridional overturning and poleward heat transport in the Atlantic and Pacific Oceans. J. Mar. Res., 40, 39-53.

Cunningham, S., and Coauthors, 2007: Temporal variability of the Atlantic meridional overturning circulation at 26.5 N. Science, 317, 935-938, https://doi.org/10.1126/ science.1141304.

de Jong, F. M., and L. de Steur, 2016: Strong winter cooling over the Irminger Sea in winter 2014-2015, exceptional deep convection, and the emergence of anomalously low SST. Geophys. Res. Lett., 43, 7106-7113, https://doi.org/10.1002/ 2016GL069596.

Evans, D. G., J. Toole, G. Forget, J. D. Zika, A. C. N. Garabato, A. J. Nurser, and L. Yu, 2017: Recent wind-driven variability in Atlantic water mass distribution and meridional overturning circulation. J. Phys. Oceanogr., 47, 633-647, https:// doi.org/10.1175/JPO-D-16-0089.1.

Ganachaud, A., and C. Wunsch, 2003: Large-scale ocean heat and freshwater transports during the World Ocean Circulation Experiment. J. Climate, 16, 696-705, https://doi.org/10.1175/ 1520-0442(2003)016<0696:LSOHAF $>2.0$. CO;2.

Grégorio, S., T. Penduff, G. Serazin, J.-M. Molines, B. Barnier, and J. Hirschi, 2015: Intrinsic variability of the Atlantic meridional overturning circulation at interannual-to-multidecadal time scales. J. Phys. Oceanogr., 45, 1929-1946, https://doi.org/ 10.1175/JPO-D-14-0163.1.

Häkkinen, S., P. B. Rhines, and D. L. Worthen, 2015: Heat content variability in the North Atlantic Ocean in ocean reanalyses. Geophys. Res. Lett., 42, 2901-2909, https://doi.org/10.1002/ 2015 GL063299.

Hogg, N. G., and H. Stommel, 1985: On the relation between the deep circulation and the Gulf Stream. Deep-Sea Res., 32, 1181-1193, https://doi.org/10.1016/0198-0149(85)90002-0.

Jayne, S. R., and J. Marotzke, 2001: The dynamics of ocean heat transport variability. Rev. Geophys., 39, 385-411, https:// doi.org/10.1029/2000RG000084.

Kanzow, T., and Coauthors, 2010: Seasonal variability of the Atlantic meridional overturning circulation at $26.5^{\circ} \mathrm{N}$. J. Climate, $\mathbf{2 3}$ 5678-5698, https://doi.org/10.1175/2010JCLI3389.1.

Lumpkin, R., and K. Speer, 2007: Global ocean meridional overturning. J. Phys. Oceanogr., 37, 2550-2562, https://doi.org/ 10.1175/JPO3130.1.

Marshall, J., and F. Schott, 1999: Open-ocean convection: Observations, theory, and models. Rev. Geophys., 37, 1-64, https://doi.org/10.1029/98RG02739.

McCarthy, G., and Coauthors, 2012: Observed interannual variability of the Atlantic meridional overturning circulation at $26.5^{\circ}$ N. Geophys. Res. Lett., 39, L19609, https://doi.org/10.1029/ 2012GL052933.

—_, and Coauthors, 2015: Measuring the Atlantic meridional overturning circulation at $26.5^{\circ}$ N. Prog. Oceanogr., 130, 91-111, https://doi.org/10.1016/j.pocean.2014.10.006.

Pickart, R. S., and W. M. Smethie, 1993: How does the deep western boundary current cross under the Gulf Stream? J. Phys. Oceanogr., 23, 2602-2616, https://doi.org/10.1175/ 1520-0485(1993)023<2602:HDTDWB > 2.0.CO;2.

_ , F. Straneo, and G. W. K. Moore, 2003: Is Labrador Sea water formed in the Irminger basin? Deep-Sea Res. I, 50, 23-52, https://doi.org/10.1016/S0967-0637(02)00134-6.

Pillar, H., P. Heimbach, H. Johnson, and D. Marshall, 2016: Dynamical attribution of recent variability in Atlantic overturning. J. Climate, 29, 3339-3352, https://doi.org/10.1175/ JCLI-D-15-0727.1. 
Rhines, P. B., and W. R. Young, 1982: A theory of the wind-driven circulation. I. Mid-ocean gyres. J. Mar. Res., 40, 559-596.

Williams, R. G., V. Roussenov, D. Smith, and M. S. Lozier, 2014: Decadal evolution of ocean thermal anomalies in the North Atlantic: The effects of Ekman, overturning, and horizonal transport. J. Climate, 27, 698-719, https://doi.org/10.1175/ JCLI-D-12-00234.1.

Yang, J., 2015: Local and remote wind-stress forcing of the seasonal variability of the Atlantic meridional overturning circulation (AMOC) transport at $26.5^{\circ}$ N. J. Geophys. Res. Oceans, $\mathbf{1 2 0}$, 2488-2503, https://doi.org/10.1002/2014JC010317.
Young, W. R., and P. B. Rhines, 1982: A theory of the wind-driven circulation II. Gyres with western boundary layers. J. Mar. Res., 40, 849-872.

Zhao, J., and W. Johns, 2014a: Wind-driven seasonal cycle of the Atlantic meridional overturning circulation. J. Phys. Oceanogr., 44, 1541-1562, https://doi.org/10.1175/JPO-D13-0144.1.

, and,$- 2014 \mathrm{~b}$ : Wind-forced interannual variability of the Atlantic meridional overturning circulation at $26.5^{\circ} \mathrm{N}$. J. Geophys. Res. Oceans, 119, 2403-2419, https://doi.org/ 10.1002/2013JC009407. 